Phenomenology \& Practice, Volume 13 (2019), No. 1, pp. 42-51

\title{
The Phenomenology of the First Date after Connecting Online
}

Nicholas Jacobs, PhD Student, Department of Secondary Education, Faculty of Education, University of Alberta

Email:nick1@ualberta.ca

\begin{abstract}
The proliferation of technology has changed the ways we are able to interact with the world, and, in turn, how we are able to interact with others. In recent years, online dating applications have become commonplace for connecting with others in search of romantic relationships. This paper reflects on the phenomenology of the first date after connecting online and explores several aspects of this unique experience of introduction, expectation, and relation. What occurs between two people online that leads them to suggest meeting for the first time in the real world? How does communicating online differ from face to face encounters? Exploring the phenomenology of the first date after connecting online invites us to wonder about the nature of dating today and in the past.
\end{abstract}

Keywords: Phenomenology, online dating, technology, relationships.

\section{Introduction}

I lounge on my couch, half-focused on a Netflix show playing in the background. Late, yet not late enough for sleep, I'm bored. I open a dating app on my phone and am immediately presented with well-lit and digitally manicured photos of women, along with their age, occupation, and a brief description of themselves. My focus hovers between my television and my phone as I half-heartedly swipe left and right on the profiles, indicating whether or not I 'like' the pictures of those appearing to me. After swiping through a dozen or so profiles, an alert sounds on my phone notifying me that I have 'liked' someone who has also 'liked' me-we now have an opportunity to message each other.

Growing up, we might have fairy tale expectations of what our future courtship, family life, and marriage will be. Such tales often paint a glamorous picture of how we find a partner. These stories conjure up images of romance; Cupid's bow and arrow guiding the way towards that special someone with whom we might spend our remaining years. Yet the world of dating is 
seldom all sunshine and rainbows. Today it appears to be bound up between the surreal and the real.

Distant seem the days of the awkward moments spent building up the courage and practicing asking out on a date the classmate or girl next door; the crucial step that hopefully leads to lifelong romance. These stories we hope, when heard years later, will elicit a resounding "Awww!" or exclamations of "That's amazing!" by those who hear them. Today, such meetings seem to be giving way to the facilitated encounters of dating apps that allow people to feed their curiosity by scrolling through carefully crafted profiles to select those with whom one might be interested in getting to know. Technology allows individuals to introduce themselves and explore the other person's world without ever having to meet them face to face. Where does the first date in the digital age start?

Etymologically, a date is understood as a "time when something happened or will happen" (Online Etymology Dictionary, n.d.). There is an underlying aspect of significance to the term, for if there were nothing occurring, no sense of importance, the experience might not be worthy of being considered a date. With the date comes a potential for significance to be made and remembered, whether it is a date on a calendar or a first date. A first date in the digital age, after connecting online, may therefore be an expectation or anticipation of significance and meaning emerging from the initial face to face encounter with an individual.

Prior to the first meeting in the physical world, there is a connection that occurs based on a concoction of a complex compatibility algorithm, a healthy dose of luck, or a desperate episode involving a flurry of 'right-swiping.' At some point after connecting, the people might introduce greater vulnerability by suggesting taking this relationship from the online to the offline, from the virtual to the real. Such an invitation might be comparable to the risk one takes in asking an acquaintance, perhaps a friend or colleague, out on a romantic date. The nature of the relationship immediately is called into question tantamount in saying, "I am interested in you more than I once was, and in this act I am hopeful you feel the same." However, because online social apps can be specifically marketed towards dating, it appears there is less of a risk in asking one on a date after connecting online as compared with a personal acquaintance, friend, or colleague already known in the physical world; the app itself projects the nature of the relationship it aims to curate. In the experience of having matched with someone, there is the unspoken assumption that the trajectory of this relationship is romantically inclined. Perhaps because of this fact, there is a greater degree of safety in online matching and making of small talk.

While we can all recognize the occasion of being introduced to a stranger - perhaps through a mutual acquaintance or a required workplace setting, or even a blind date - $\mathrm{a}$ first date after connecting online seems to have its own experience of connection. The stranger we are introduced to is terra incognito - we have no sense of familiarity with this person before we are introduced to them. We might hope for the best and have expectations of where we would like for it to go, and yet it may go nowhere. The first date after connecting with someone online is different in that we may have already heard a great deal about the person through messagingthat they like long walks on the beach, or Piña Coladas, or getting caught in the rain. But we may not know if this is true or simply an element the person has put forth in order to appear charming. What reality is absent from the virtuality of meeting online? What is the experience of meeting an other or allowing oneself to be discovered in person following virtual interactions? Is this experience a validation of us or of our digital image? Do they really like Piña Coladas? 


\title{
Clash Between the Digital and the Physical Me: Initial Date as the 'Make or Break' Moment
}

\begin{abstract}
I anxiously get dressed. I check my watch - I am running several minutes behind schedule. "Why did I agree to this?" I question myself and send a quick text message to the woman I am about to meet for the first time. Searching for a parking spot as I pull up to the small restaurant, I swallow one more wave of apprehension. I check my phone and see a message from her, outlining where in the bar she is sitting and what she is wearing. I walk up to the front door, selfconscious of myself-I wonder if she has already spotted me from inside the restaurant. I enter, scanning the restaurant quickly. Her eyes and mine meet almost in unison, and we exchange a quick smile.
\end{abstract}

Apprehensive and anxious, as a young man prepares to meet his date, we may wonder what was the strength of any proceeding virtual connection. How much of a stranger is he ultimately coming to meet? As he scans the restaurant scene, seeking out the one who matches his online match, how blind is he to the reality of this first date?

Online, there is an opportunity to explore, connect, and discover digitally before attempting engagement in the material world. Apprehension may be felt wondering whether the person we have come to know online will align with whom we meet face-to- face. To build up in our imagination all that someone else has the potential to be and to be let down after meeting them is surely difficult, yet not nearly as difficult as acknowledging that the other might very well be doing the same to us! The time spent after connecting online, yet prior to meeting for the first date, is perhaps best understood as a liminal space between being unknown to one another as strangers and being in a relationship or dating. There is a safety to the online world as no real meeting needs to ever be pursued with any profiled individual. And when a decision is made to pursue a match, text exchanges or other virtual communications may clarify whether a particular match is worth making. If either decides the communication is no longer desirable, one or both might stop responding and therefore 'ghost' the other.

The blind date, on the other hand, might truly be more 'blind,' as there is less, or perhaps no, opportunity to connect before meeting whatsoever. The quick text message informing the other of being several minutes late is made possible through having already shared some connection online. The agreement to meet for a blind date may therefore be seen as a placing of one's trust into the individual acting as the catalyst for the date; the intermediary who vouches for the potential connection they see between the two blind daters. Other than this intermediary, each individual has no sense of direct connection to the other; the only conversation or connection that occurs is done through the third party who sets up the blind date. We can see how connecting with someone online already offers the opportunity to explore an other - their life, story, personality - before meeting in the physical world. And yet we may wonder how real was this digital meeting when the reality of going on a first date after connecting online can still be marked by apprehension and anxiety.

As we head to the first date, we may wonder why we chose to take the risk to bring our physical self forward. The agreement to meet in the material world is therefore an agreement to experience oneself beyond the construction of the digital identity, whereby less of a veil exists behind which each individual may hide. To risk in suggesting the relationship moves into a 
material world meet up is both a precursor to experiencing the physicality of another person, and is also an act of vulnerability, for the unspoken question resides within each individual agreeing to meet: "Will I still appeal to the other after having them see me in this way? Is this person in the material world all that I have imagined them to be?" If love begins with value (Vacek, 1982), the relationship may have begun long before the first date; however, there is something about the moment of first connection in the material world that is profoundly different than each message exchanged leading up to the moment "her eyes and mine meet almost in unison." How critical is the moment of initial experience in the physical world towards setting the stage of how the rest of the date will go?

I take an Uber to where we're meeting, wondering what it is I will order at the restaurant. I show up a little bit late. He is already there. I walk in and I see him-he is far older than how he looked in his pictures. "I'm never going to see this guy again," I think to myself. "Whatever. I'm going to make the best of it now. He saw me-I can't leave." Feeling a sense of disappointment, I walk over to the table. I feel awkward. We don't hug, but he stands up and says hello. I'm uncomfortable.

Despite the energy that was taken by both parties to connect online, the instantaneous moment of initial exposure to the other in the 'real world' can appear to be the 'make or break' moment for the budding relationship. Perhaps there is a quality of the online relationship that fails to afford the texture of that which can be grasped within a real world meeting. After all, an online profile might not show confidence conveyed in a strong posture, relaxedness seen in a flirtatious flip of the hair, or vulnerability seen in a downward gaze. Through a screen, these reactions may be muted, elongated, delayed, diluted, or falsely amplified. Because each digital identity can be constructed so as to highlight only the aspects of the physical self the person chooses to put on display, there can be moments when the real life dater pales in comparison to how they have been experienced in the virtual, since all other nuanced layers of the self can exist behind the veil of technological safeguards.

How does such infinite nuance in the flesh relate to relationality? Adams (2014), exploring the experience of the other in online classrooms, understands that encountering one's name online does not result in any sort of presence being called into existence, but instead is merely "[a name] gesturing toward a person with whom I am not yet familiar" (p. 56). Yet, with time and a number of reciprocated interactions online, the online presence of the other can become one with whom we feel a sense of relationship. Therefore, the digital sphere of technology does afford the opportunity to create an aspect of familiarity and relationality, although the encounter in the physical realm can be much different. This difference might suggest that some essential energy exists between two individuals meeting for the first time; an energy that remains out of the grasp of what is possible to experience in the online world.

\section{Who Would You Like to Meet? The First Date as Navigating One's Self}

I listen to music as I walk to the restaurant where we've planned to meet. The walk gives me time to wonder about how the date might go, and we seem to have some things in common based on our messaging conversation, which makes me 
excited about the date. I feel awkward thinking about how it is I'd like to present myself to this person. I don't want to come across too aggressive, but I also want to be chill and express interest if I'm interested in her. I feel more anxious and stressed as I get closer to the restaurant, wondering how the date will go. I contemplate how I should introduce myself-is a hug too forward? A handshake too formal?

The moments leading up to the first date may be ones not only of anxiety and excitement, but also may be an opportunity to deliberate with oneself about what aspects they might choose to show off. As he prepares for this experience, he realizes he can present multiple aspects of his character to his date, aware of how he would like to see himself "come across" to her. He could pretend to be anyone! The only pre-existing information his date has to draw from is the shared messaging back and forth, pictures each of them chose for their profiles, and perhaps whatever sort of cyber-stalking each of them (or both!) chose to do over social media. To enter into a first date is an invitation to not only discover someone else, but simultaneously to allow oneself to be discovered in ways that differ from other interactions. Two people agree to engage in a rendezvous in search of some spark or chemistry that might lead to another, and perhaps another, opportunity to meet. It may not only be an occasion that provides answers to curiosities about this person, but it is also the same reciprocated: an occasion to have the other person's wonderings about me verified. All the while there is an awareness that what one might be feeling is not at all reciprocated by the other; my experience of you is not the same as yours of me- the connection one feels is left hanging without a place to land.

Taking time to think about how the date might go suggests the first date after connecting online may hold a particularly unique experience of wonder - a wonder originating from all that cannot become known in the digital realm. The getting-to-know that occurs online may cultivate a sense of wonder; a curiosity towards how much more we may come to know through meeting in person. The first date after connecting online becomes the seesawing between the usual and the unusual investigated in Verhoeven's (1967/1972) exploration of wonder-oscillating between the usual customary experience of communicating and the unusual experience of transitioning such communication from the online realm into the physical. The contrast between these two worlds coupled with romantic exploration is one unique to the experience of the first date after connecting online. Perhaps the wonder-inducing clash between these two realms is personified by the dater's contemplation in deciding between a handshake or a hug, as it may represent an uncertainty of what the relationship calls for in the present moment of first meeting.

The qualities I attempt to highlight for an other on this initial encounter are taken to be who I am outside of any other given role I might play in my life, whether it be employee, friend, parent, etc. On the first date it is Nick, and Nick alone. If I attempt to put forth qualities of my character that cannot be lived out long-term - no matter how much I think I can be anyone I want to be on this first date - the disguise remains with me for however long this relationship might last. The timeline might be for the extent of the first date, or perhaps long into the future if there is a lasting connection. It may be that the dater's experience of awkwardness, anxiety, and stress all reflect an inner negotiation of what he might feel best to display upon first meeting. To put our best self forward that is not a reflection of who we find ourselves to truly be, not only are we implicated in feigning any connection that occurs, but we are also questioning the quality of the connection itself; for how deep, natural, and intimate is a connection that is founded upon one or both of the daters' inauthenticity? 


\title{
Conversing for the First Time: Meeting in a New Way
}

\begin{abstract}
She stands up from the table as I walk over. I initiate a hug; she reciprocates. We hug and both sit down at the table-myself directly across from her. I am hyperaware of my body and my thoughts as the conversation begins. The waitress approaches our table and we negotiate what we each might drink and discuss how hungry each of us are. I am nervous, and I constantly think about how to best present myself to the woman across from me. I am conscious of the amount of eye contact I make with her as we speak, and in my mind, I am questioning every statement and behaviour I make. It is very difficult to listen and remember what she is saying to me. The waitress sets my drink in front of me, and I am thankful for having a place my hand can occupy.
\end{abstract}

The first date after connecting with someone online might be understood as any other first date, marked with experiences of awkwardness, nervousness, or self-consciousness. However, the set up leading to this experience is unique in that both individuals have negotiated and agreed upon this first 'face to face' encounter; acknowledging the in-person experience is different from communicating over text messages in the online realm. Perhaps what makes the first date after connecting online unique is that aspects of these emotions are the result of recognizing what is at greater stake in a physical interaction - that there is a greater awareness of the degree of safety that exists when communicating online. In my flesh I am exposed in almost every way that is socially possible - my identity as projected from my being in my mannerisms, spoken word, outfit, and the like, is a culmination of the entirety of how I present myself. The text messages I send, on the other hand, are but a shade, and the device through which the messages are sent acts as an apparatus through which I experience an other. The contrast between communication in the online realm versus the vulnerability felt in the physical opens space for the natural and expected first date emotions of awkwardness, nervousness, or self-consciousness to be amplified.

Ihde (1979) sees this relation to technology as one of transparency, understanding that technology has the capacity to extend oneself towards an other. Despite such extension, there is a simultaneous reduction of the experience as described above. In my desire to converse with she who has caught my attention, I extend myself through the device in the form of written messages, sharing aspects of my subjectivity with her. I can learn from, flirt with, and enjoy her company in the absence of such company. This absence is the reduction to which Ihde speaks. In such a manner of communicating, I can merely interpret the written messages read through my device, yet I am unable to connect with her subtle glances, her fragrant scent, or the way the sun catches a sparkle in her eye. Mersch (2010) suggests that the relational construction of experiential extension/reduction created by the use of technology suggests that the device utilized for messaging becomes diaphanos; a 'third' space between two communicating individuals (as cited in Adams, 2014, p. 60).

Despite the technological interface rendering the face effaced, the digital device simultaneously exists as a required instrument for communicating. As an intermediary, the technology extends oneself towards an other, reaching out to allow for contact, despite the quality of contact being a reduction of that which can be experienced in the flesh. Additionally, an individual can receive a message from an other and not reply for minutes or hours, thinking 
and re-thinking about how best to respond. Attention is required only for the extent to which I form and send the next message. Upon the message being sent, focus and attention can shift towards anything else in the individual's world. These bite-sized moments of devotion, relying solely on constructing appropriate responses to the other's messages over a span of time, require as much or as little effort as each individual is willing to put forth, and therefore, may be a more safe way of communicating. There may be greater safety in this form of communicating relative to a physical face to face encounter. To say something the other might interpret as wrong, offputting, or offensive in the digital realm might only be met with silence on the other end, leaving the sender able to interpret or misinterpret such silence in a number of ways. Online silence also creates greater space for one to wonder whether or not a comment was taken in the wrong way.

An encounter in the physical is different - communication is occurs in a faster, more back and forth conversation than what occurs in the digital world. We each become aware of aspects of the other's physicality, such as eye contact, their gestures, the tone and quality of their words, their perfume, etc. requiring more consideration from moment to moment by each. It can more easily be understood when something said might have been taken the wrong way through experiencing the other's physical reactions through their gestures and body language. To make a strong impression on someone in the everyday requires far more than just witty words and appropriate sentence structure. We are also required to be engaged with what is occurring in each moment with the other, or we risk being interpreted by them as not interesting; that a connection in this moment is not occurring. Perhaps it is a dance between both how we aim to impress and hope to be engaged, the navigating of one another in the face to face moment, that is the catalyst for a connection to be felt in the space amid each other.

The physicality of the other may act as a mirror onto which one's own self is projected. If I say something charming or clever, I can experience the response through the physicality of the other by means of a smile or laugh. I may then feel a sense of validation through how I am mirrored by the other. In texting conversations this mirror may exist, however in a tempered manner and through the digital screen of my device. Should I offer the same charming remark, it might be met with an emoticon or 'lol,' another bite-sized moment of focus or attention. It might also result in a null response, opening for the possibility of being interpreted in multiple ways. The mirror of the other in the everyday is one of far greater, perhaps infinite, nuance through which we have the opportunity to experience ourselves in the reactions we receive from the other. Somehow between the digital and physical worlds these bite-sized moments are translated into sustained, ongoing communication. The transition of one form of communication to the other is not always easy or smooth.

\section{Connections Missed}

The conversation is mostly comprised of him talking at me about things I don't care about. I want to leave but I also don't want to be rude. I endure the conversation and time passes quite slowly. I'm aware that he looks far older in person than he does in the pictures on his profile, and I feel somewhat gross because of this. I know the waitress can hear some of our conversation, and I wonder what she is thinking-I wonder if she is curious about what this young woman is doing with this old loser who keeps talking about himself. We order another drink, and the time seems to pass faster. It gets late, and I tell him I need 
to go. He tells me he wants to hang out again, and although I don't want to I say, "OK, sure." I call an Uber, and when it arrives, I get in. I feel frustrated and that I had wasted my time. I begin swiping on Tinder.

Within the digital world there is a great capacity for illusion and deception. There is an aspect of trust that the pictures one has become familiar with will accurately represent whom they are agreeing to meet in the physical. And yet, while we may choose to put our best digital self forward online, there is far less capacity for deception in the infinitely nuanced world of the physical.

Perhaps with the decision to meet for a first date there is an unspoken agreement that the date will run its course despite a lack of connection felt by one, or both, individuals. The quality of conversation appears central to the experience, partially requiring that a reciprocal dialogue take place without someone talking to a far greater length than the other, running the risk of being interpreted as rude or egotistical. Resulting in what might feel like entrapment, one may be reduced to having to "endure" the experience at the recognition that enjoyment might not come until, perhaps, the next round of drinks. Any expectation or anticipation about the first date-nervousness experienced at what might come from this initial encounter-may be replaced with disappointment, frustration, or downright regret. How paradoxical such an experience is to the ever present and waiting potential matches that might come at any moment from swiping on an online dating app.

And thus, the first date can become the experience of "waste." The waste might extend beyond just the time invested in the first date, towards the greater effort and time from when they first connected online and had come to know one another. The waste is perhaps that of time sacrificed and also wasted potential of that which one of both hoped could have been. The understanding that there is something we hope to find in the experience with an other, a sense of connection and chemistry that began the process of desiring to connect with an other, all lends itself to the "waste" that is experienced as we sit alone in the Uber back home, finding ourselves engrossed in the online dating app from which the experience began; an act towards redeeming the hope that inspires us towards seeking the connection we desire.

\section{Connections Made}

I'm at a coffee shop doing schoolwork, and we realize through messaging that we are both in the near vicinity. He suggests we meet for coffee. I'm wearing a cute dress and realize I look great so I agree to him coming to meet me where I am. I check the door every once and awhile for someone that might look like who I know from his pictures. I feel excited.

I'm enjoying exploring the things we have in common, and I don't want this experience to end. We stay for probably thirty minutes after finishing our coffees, and I sense we're both dropping hints that we don't want this date to end. We leave together and explore campus, then end up getting food and drinks. As time continues to pass and the date goes on longer and longer, I feel like I am fourteen again in the sense that I've lost contact with the normal responsibilities of my 
day. I feel very carefree, and I begin to wonder if this is a story that I might be telling for years.

A strong connection might be experienced as carefreeness - a sense where the connection that is being felt thus becomes a priority within the temporal realm of the first date. Is the connection itself - whether considered an energy, force, or otherwise-created by the two individuals coming together, as if each individual is a necessary ingredient for some recipe of romance? When the "normal responsibilities of my day" fade into the background, everything else is rendered irrelevant - the connection felt and shared with an other seems to take precedence.

Any connection shared in the digital realm appears to pale in comparison to that which has the potential to be felt in the flesh. When two people share a connection (the mystery of which we might be best leaving up to the philosophers and poets to ponder upon) it might have started online, but perhaps meeting in the physical allows for it to blossom in a new and different way. Each person offers an aspect of themselves to the other in a way that cannot be cloaked by their online personality. The connection they experience perhaps becomes something beyond each of them-one and an other create something more; the connection operating as that which moves a relationship into greater depths.

It is the desire for connection between two people that appears to underscore the world of dating. Although we may grow up with certain expectations of how we might come to know and experience this connection, the advancement of technology provides a new way for us to journey towards such a relationship. Technology allows us to connect to a limitless number of people, yet at the end of the first date after connecting online, we return to the same desire for a specific experience of connection with one. Perhaps it matters not to the meaningfulness or longevity of the relationship whether the date begins from an online connection, blind date, or otherwise- no matter where it begins, what matters is where it ends up, which might be a place that is deeply familiar for us all. Recalling that meaning and significance are deeply ingrained in what might constitute the date, the desired connection may be the destination to which such meaning and significance lead. Perhaps an element of this connection is embodied in Klimt's (1907-1908) painting The Kiss, whereby the golden outfits adorned by each character come together, each perceptible only by the patterns of the clothes that separate them. And yet there is a third component - $\mathrm{a}$ golden halo stemming from each of their robes, adorning, encircling, encapsulating the two in some way beyond that which each of them could muster on their own. It is the journey of each individual to explore and understand the degree to which they each feel such longed for connection with the other. 


\section{References}

Adams, C. (2014). What's in a name? The experience of the other in online classrooms. Phenomenology \& Practice, 1, 51-67.

Date [n.1]. (n.d.). In Online Etymology Dictionary, Retrieved January 10, 2019, from https://www.etymonline.com/word/date\#etymonline_v_783.

Ihde, D. (1979). The experience of technology \& perception transformed. In Technics and Praxis (pp. 3-27). Boston: D. Reidel Publishing.

Klimt, G. (1907-1908). The Kiss [Oil and gold leaf on canvas]. Österreichische Galerie Belvedere, Vienna.

Vacek, E. V. (1982). Scheler's phenomenology of love. The Journal of Religion, 62(2), 156-177.

Verhoeven, C. (1972). The philosophy of wonder: An introduction and incitement to philosophy. London: The MacMillan Company. 